\title{
ESTUDO DO MOVIMENTO DE BENNETT
}

\author{
Dr. Ézio Teseo Mainieri* \\ C.D.,M.S.D.
}

MAINIERI, Ézio Teseo - Estudo do movimento de Bennett, Revista da Faculdade de Odontologia, Porto Alegre, 25:23-31, 1983.
Descritores: Oclusão dentária - Mandíbula, Movimentos - Mandíbula, Cabeça de côndilo

\section{RESUMO}

Quarenta pacientes, sendo vinte do sexo masculino e vinte do sexo feminino, foram selecionados a partir de um grupo individual. Todos os pacientes eram portadores de no mínimo vinte e seis dentes. Impressões em alginato foram tomadas de cada paciente em suas arcadas superior e inferior. Após cada impressão individual foram realizadas determinações de eixo-intercondilar para cada paciente sendo que o eixo determinado foi tatuado em todos os pacientes. Para localização do modelo superior no gnathothesiometer um arco facial arbitrário foi utilizado, assim como um registro de relação cêntrica para cada paciente foi realizado para relacionamento do modelo inferior ao modelo superior. Após a montagem final dos modelos, dois registros laterais foram determinados no paciente (um direito, um esquerdo) e transferidos ao instrumento para medições.

Os resultados mostraram que o movimento de Bennett ocorreu numa mé- dia de $1,5 \mathrm{~mm}$ e isso pode ser relatado aos esquemas oclusais para cada paciente.

\section{INTRODUÇÃO}

Basicamente os movimentos laterais da mandíbula iniciam na posição de relação cêntrica e são identificados pela excursão mandibular para o lado direito e esquerdo, enfim uma combinação de movimentos rotatórios com uma translação, formando um movimento assimétrico.

O lado em questão e de maior importância para o nosso trabalho é aquele no qual o movimento orienta-se, chamado lado funcional ou de trabalho, o qual apresenta um nítido movimento lateral chamado Movimento de Bennett. Durante muitos anos Gysi determinou esse movimento através de seu traçado em forma de arco gótico.

Ao analisarmos uma excursão lateral, a mandíbula gira sobre um eixo imaginário localizado mais atrás e fora do côndilo funcional, e ao passo que este

*Professor Regente da disciplina de Oclusão do Departamento de Odontologia Conservadora da Faculdade de Odontologia da U.F.R.G.S. 
côndilo funcional desvia-se para fora e as vezes também para baixo. Esta movimentação total correspondente a uma lateralização condilar conhecida como movimento inicial de deslocamento do côndilo "side shift".

Alguns indivíduos não apresentam o deslocamento lateral do côndilo funcional, apenas rotação, não havendo portanto transláções. A média encontrada em outros grupos técnicos, por outros pesquisadores é em média 1,5 $\mathrm{mm}$.

A explicação básica do Movimento de Bennett segundo alguns autores é de que a parede interna da fossa glenóide no lado de balanceio é mais aberta que a direção geral do movimento de rota. ção e por ação do músculo pterigoideo externo o côndilo é tracionado para dentro, o qual orienta toda a mandíbula para o lado oposto. Outros autores sustentam que ao puro sinergismo de ação dos Pterigoideos Externos.

A importância do Movimento de Bennett inicial é sempre expressado em décimos de milimetro, e sua influência sobre a oclusão dá-se primeiramente influenciando a largura dos sulcos centrais dos dentes posteriores e sua importância ainda está relacionada com o outro elemento do movimento que é o ângulo de Bennett, que sofre influência quantitativa do Movimento de Bennett e torna-se importante para evitar futuras interferências oclusais, tanto em procedimentos de diagnóstico como clínicos.

\section{MATERIAL E MÉTODOS}

Quarenta pacientes, sendo 20 do sexo feminino e 20 do sexo masculino, foram selecionados a partir de um exa- me individual prévio. Os referidos pacientes todos portadores de no mínimo 26 dentes, não apresentavam problemas de oclusão bem como sintomatologia articular ou mesmo muscular. 0 exame das alterações do sistema mastigatório foram levadas a efeito por meio de exame clínico de palpação dos principais músculos mastigatórios a saber masseter, pterigoideo interno, pterigoideo externo e músculo temporal bem como análise imediata da oclusão a qual constou de detecção de interferências oclusais, em posições básicas da mandíbula como relação cêntrica, oclusão cêntrica, lateralidade direita e esquerda. Foram ainda realizados exames individuais registrando possiveis ruídos articulares, interferências na abertura máxima funcional e mal posicionamento dentário.

Ápós o minucioso exame de cada paciente os mesmos foram moldados individualmente, com alginato em suas arcadas superior e inferior e a partir daí obtidos modelos em gesso pedra especial os quais não apresentavam qualquer defeito para evitar interferências nas montagens futuras. Moldados os $\mathbf{4 0}$ pacientes, os modelos foram numerados e colocados em ordem, de tal forma que os pacientes observassem o mesmo escalonamento determinado durante a fase de moldagem. Com o auxílio de um instrumento, o arco facial cinemático, determinamos o eixo intercondilar real de cada paciente. A determinação individual do eixo tornou muito mais preciso o estabelecimento dos pontos colocados sobre o plano superficial cutâneo, evitando-se a determinação tradicional desses pontos através dos planos de referência arbitrários. $O$ arco facial cinemático com suas hastes laterais reguláveis tanto verticalmente quanto antero-pos- 


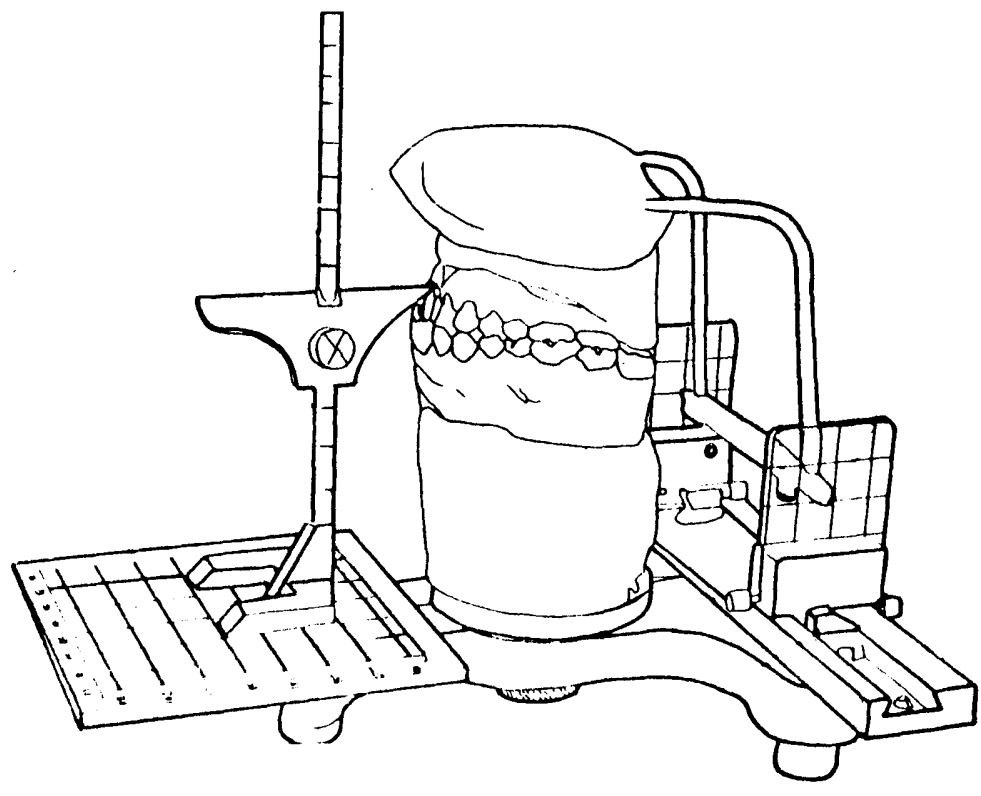

FIGURA 1 - DESENHO ESQUEMĀTICO DO GNATHO-THESIOMETER

teriormente, nos proporcionaram não só precisão como maior acesso às condições reais de cada paciente. Obtido o ponto de referência intercondilar o mesmo foi tatuado com tinta nanquim com o próprio pino condilar do arco facial cinemático permanecendo indelével sobre a pele. O uso de pasta zinco-enólica foi adotado como meio de fixação da forquilha ao paciente, para posterior conexão aó arco.

Com os quarenta pacientes tatuados individualmente, foram iniciadas as montagens do modelo superior com um arco facial estático especialmente dese- nhado para relacionamento do eixo intercondilar real do paciente determinado previamente através do arco facial cinemático.

Registrada esta relação transferimos para o Gnathothesiometer, adaptando o modelo do caso em questão ao registro inserido na forquilha do arco facial e só então fixamos com gesso todo o conjunto. Montado o modelo superior com as faces oclusais voltadas para cima (posição invertida) iniciamos a obtenção de registros visando montar o modelo inferior. 
Cera Alluwax e Cuperwax impregnadas respectivamente com pó de alumínio e cobre, foi usada pelas suas características de manter por mais tempo a sua plasticidade proporcionando maior tempo de trabalho e impressões mais precisas.

Uma placa de registro em alumínio na formação do elemento de fixação da cera foi aplicada sobre as superfícies oclusais dos dentes correspondentes à arcada inferior, impressionando assim na cera após a sua plastificação, todos os dentes do modelo inferior.

De posse desses registros estabelecemos condições de transferi-los ao Gnathothesiometer e fixá-lo ao aparelho por meio de gesso comum.

Completada a moldagem estabelecemos condições de iniciarmos as medições que se processarão sobre um dispositivo milimetrado colocado na parte posterior do Gnathothesiometro e que nos dá a dimensão exata do movimento a que nos propomos medir, o Movimento de Bennett.

Recolhidos esses dados através de duas mordidas em cera laterais (lateralidade direita e esquerda).

Executamos esta operação individualmente nos 40 casos selecionados, coletando os dados correspondentes em fichas individuais as quais relatam toda a seqüência de passos executados no paciente e finalmente transportamos todos esses dados finais para uma ficha geral a fim de que tabulando e analisando em conjunto pudéssemos obter os resultados propostos no início da pesquisa.

\section{RESULTADOS OBTIDOS}

Os resultados obtidos a partir das medições realizadas nos quarenta casos podem ser apreciados pela observação da tabela 1 e 2 vendo-se o número de casos que apresentavam medidas variáveis de "immediate side shift", tanto para o lado'direito como para o lado esquerdo.

Houve uma maior concentração de movimentos laterais em torno de 1.8 a 2.0 quando o movimento de Bennett foi registrado do lado esquerdo na movimentação lateral esquerda da mandíbula. (TABELA 2)

A TABELA 1 nos mostra que a concentração maior de movimentos laterais foi em torno 1.2 a 2.4 quando o Movimento de Bennett foi registrado do lado direito na movimentação lateral direita da mandíbula.

Pela tabulação por intervalos de classe a incidência maior tanto para a movimentação lateral para o lado esquerdo como para o lado direito ocorreram nos intervalos de classe compreendidos entre 0.6 a $2.4 \mathrm{~mm}$.

A medida média de movimentação lateral direita obtida quando a mandibula movimentou-se para o lado direito, portanto Movimento de Bennett do lado direito foi de $1.53 \mathrm{~mm}$. Ao passo que a média de movimentação lateral para o lado esquerdo foi registrada em média em torno de 1.48. Portanto a média geral estabelecida de movimentação lateral do côndilo de trabalho quando a mandíbula executa movimento de lateralidade ativa (trabalho), foi de 1.51 $\mathrm{mm}$.

\section{RESULTADOS}

Os dados obtidos a partir das medições realizadas nos 40 casos estudados podem ser analisados a partir das Tabelas que se seguem. 


\section{TABELA 1}

Distribuição das freqüências absolutas e relativas das medidas obtidas em lateralidade direita, correspondente ao Movimento de Bennett em 40 pacientes (sexo masculino e feminino)

\begin{tabular}{|c|c|c|}
\hline Intervalo de classe & N. de casos & Porcentagem \\
\hline $0,0 \ldots \ldots \ldots \ldots . . . . .6,6$ & 6 & $15,0 \%$ \\
\hline $0,6 \ldots \ldots \ldots \ldots \ldots \ldots \ldots \ldots, 1,2$ & 9 & $22,5 \%$ \\
\hline $1,2 \ldots \ldots \ldots \ldots \ldots 1,8$ & 8 & $20,0 \%$ \\
\hline $1,8 \ldots \ldots \ldots \ldots \ldots 2,4$ & 15 & $37,5 \%$ \\
\hline $2,4 \ldots \ldots \ldots \ldots \ldots 3,0$ & 2 & $5,0 \%$ \\
\hline TOTAL & 40 & $100,0 \%$ \\
\hline
\end{tabular}

\section{TABELA 2}

Distribuição das freqüências absolutas e relativas das medidas obtidas em lateralidade esquerda correspondentes ao Movimento de Bennett em 40 pacientes (sexo feminino e masculino)

\begin{tabular}{|c|c|c|}
\hline Intervalo de classe & NO de casos & Porcentagem \\
\hline $0,0 \ldots \ldots \ldots \ldots \ldots . \ldots, 6$ & 3 & $7,5 \%$ \\
\hline $0,6 \ldots \ldots \ldots \ldots \ldots 1,2$ & 15 & $37,5 \%$ \\
\hline $1,2 \ldots \ldots \ldots \ldots \ldots 1,8$ & 8 & $20,0 \%$ \\
\hline $1,8 \ldots \ldots \ldots \ldots \ldots 2,4$ & 9 & $22,5 \%$ \\
\hline $2,4 \ldots \ldots \ldots \ldots \ldots 3,0$ & 5 & $12,5 \%$ \\
\hline
\end{tabular}




\section{TABELA 3}

Deslocamento lateral do côndilo direito (immediate side shift) em lateralidade direita em $\mathbf{4 0}$ pacientes

MEDIDA DO MOVIMENTO EM MM.

NÚMERO DE CASOS

\begin{tabular}{ll}
\hline 0,1 & 1 \\
0,4 & 2 \\
0,5 & 3 \\
0,8 & 1 \\
0,9 & 1 \\
1,0 & 2 \\
1,1 & 3 \\
1,2 & 2 \\
1,3 & 1 \\
1,4 & 1 \\
1,7 & 3 \\
1,8 & 3 \\
1,9 & 3 \\
2,0 & 3 \\
2,1 & 7 \\
2,3 & 1 \\
2,4 & 1 \\
2,5 & 1 \\
3,0 & 1 \\
\hline
\end{tabular}

Número Total de casos

40

R. Fac. Odont. P.A. 


\section{TABELA 4}

Deslocamento lateral do côndilo esquerdo (immediate side shift) em lateralidade esquerda em 40 pacientes

$\begin{array}{ll}0,1 & 1 \\ 0,4 & 1 \\ 0,5 & 1 \\ 0,7 & 2 \\ 0,8 & 2 \\ 1,0 & 4 \\ 1,1 & 3 \\ 1,2 & 1 \\ 1,3 & 3 \\ 1,4 & 2 \\ 1,6 & 1 \\ 1,8 & 4 \\ 1,9 & 3 \\ 2,0 & \\ 2,1 & \\ 2,2 & \\ 2,5 & 1 \\ 2,7 & \\ 2,8 & 1 \\ 2,9 & 2\end{array}$

\section{DISCUSSÃO}

A determinação clínica do Movimento de Bennett também chamado na literatura mundial de Immediate Side Shift, é importante pela sua influência sobre as faces oclusais dos dentes. Pois toda intervenç̧ão sobre determinada morfologia oclusal implica na observação quantitativa do Movimento de Bennett, que tem influência direta

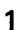

1

1

2

2

4

3

1

3

2

1

4

3

4

1

1

2

1

1

1

.

1

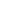

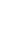

4

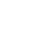

3

\section{0}


shifts adaptáveis de fábrica), assim como os Articuladores Totalmente Ajustáveis oferecem a possibilidade de diminuição de erro já que associam o Movimento e o Ângulo de Bennett de forma conjunta e não como ocorre em todos os demais articuladores semiajustáveis arcon e non-arcon em que o Ângulo de Bennett é registrado (Progressive Side Shift), unicamente. Esta ação conjunta do deslocamento lateral linear, com uma regulagem angular, a primeira sendo o movimento de Bennett aqui determinado, o segundo o ângulo de Bennett nos proporciona uma movimentação curva do côndilo em relação à real parede lateral da cavidade glenóide e conseqüentemente melhores resultados na ação do profissional em procedimentos que envolvam toda e qualquer alteração da morfologia oclusal.

\section{CONCLUSÕES}

1) Os dados tabulados mostraram que a média do Movimento de Bennett registrada para uma amostragem da população brasileira foi de $1.51 \mathrm{~mm}$.

2) A média quantitativa obtida está dentro dos pa ões registrados por outros pesquisac res os quais usaram outros procedim tos na determina. ção do fenômeno.

3) Os dados aqui determinados mostram a relação direta entre uma boa articulação dentária e a quantidade estável de movimentação lateral.

4) O movimento lateral ocorre sempre em maior quantidade no início do deslocamento não havendo praticamente aumento na fase final do movimento.
5) Esta movimentação horizontal-lateral confirmou ser determinada com maior exatidão no Gnathothesiometro do que em Articuladores.

\section{SUMMARY}

Forty patients, twenty female and twenty male were selected, from a individual group. All the selected patients had twenty six teeth or more. Individual alginate impressions were takenin the upper and lower arches. After each individual impression had taken, an individual hinge axis procedure was effectived with a kinematic face - bow. Determined the hinge axis each patient was tatued and a arbitrary face - bow was used to mount the upper cast in the gnathothesiometer. The lower cast was related to upper cast throught a centric relation registration (individual). Mounted both casts (upper and lower) in the instrument, two laterals bite registration were taken (one rigth, one left) on the patient and transfered to the gnatho-thesiometer for measurements.

The results showed that Bennett moviment, occurred in $1,5 \mathrm{~mm}$ average and thus was related to an intimate occlusal scheme for each patient. 


\section{REFERÊNCIAS BIBLIOGRÁFICAS}

1. ADMS, S. H. \& ZANDER, H. A. - Functional tooth contacts in lateral and centric occlusion. J. Am. Dent. Assoc., 69:465-7:3, 1964.

2. JONES, R.G. - The physiological role of dental occlusion in the masticatory system. Indiana, University. School of Dentistry, 1965, 148p. Master's thesis.

3. HJORTSJÖ, C. H. - Studies on the mechanics of the temporomandibular joint. Kunggliga fysiografiska sallskapets handlingar 66, 1955.

4. POSSELT, UIf. - An analizer from mandibular positions. J. Prosthet. Dent., 7(3) :368-74, 1957.

5. GUICHET, N. F. - Inicial reference. In: - Procedure for occlusal treatment. Anaheim, Denar Corp., 1969. Chap. 3, p. 34.

6. GUICHET, N. F. - Occlusion. A teaching manual. Anaheim, Denar Corp., 1977. p. 89.

7. GUICHET, N. F. - Relating condilar movement to oclusal anatomy. In: . - The Denar Mark /I system. Anaheim, Denar Corp., 1976.

Chap. 3.

8. NEFF, Peter. Occ/usion and function. Washington, D. C., Georgetown University. School of Dentistry, 1975. 